\title{
Segmental Spinal Muscular Atrophy Localised to the Lower Limbs First case from Oman
}

"Roshan Koul, ${ }^{1}$ Amna Al-Futaisi, ${ }^{1}$ Khalid Al-Thihli, ${ }^{2}$ Zandre Bruwer, ${ }^{2}$ Patrick Scott ${ }^{2}$

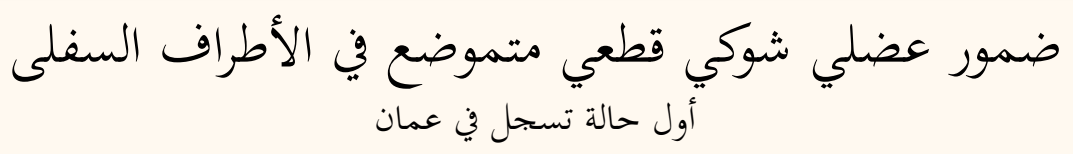

روشان كول، آمنة الفطيسية، خالد الذهلي، زاندر بروير، باترك سكوت

ABSTRACT: Spinal muscular atrophy (SMA) is a genetic lower motor neuron disease. It usually involves all of the skeletal muscles innervated by the anterior horn cells of the spinal cord. In rare cases, there is also localised involvement of the spinal cord. We report a 10-year-old boy who presented to the Sultan Qaboos University Hospital, Muscat, Oman, in 2015 with muscle weakness restricted to the lower limbs. The presence of a homozygous deletion within the survival of motor neuron 1 gene confirmed the diagnosis of SMA. To the best of the authors' knowledge, this is the first report of an Omani patient with segmental SMA involving only the lower limbs. Treatment for this rare and relatively benign form of SMA is symptomatic and includes physiotherapy.

Keywords: Spinal Muscular Atrophies of Childhood; Spinal Muscular Atrophy, Segmental; Muscle Weakness; Pes Cavus; Case Report; Oman.

الملخص: يعد الضمور العضلي الشوكي القطعي مرضـا وراثيا بـالعصبون الحركي السفلي. ويصيب المرض عادئ عادة كل العضلات الهيكلية

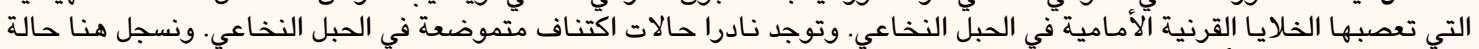

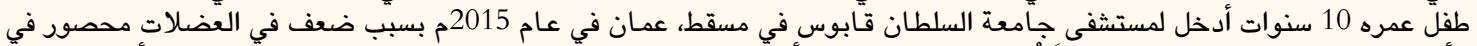

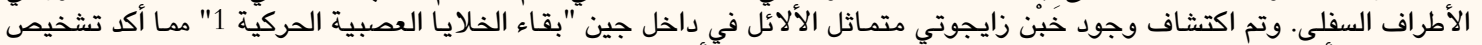

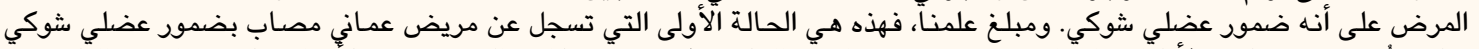

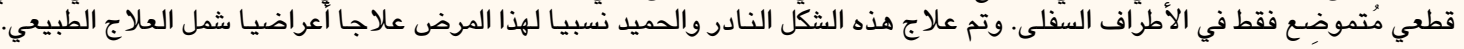

الكلمات المفتاحية: حالات الضمور العضلي الشوكي عند الأطفال؛ ضمور عضلي شوكي، قطعي؛ ضعف عضلي؛ قدم خمصية؛ تسجيل حالة؛ عمان.

A UTOSOMAL RECESSIVE SPINAL MUSCULAR atrophy (SMA) is a genetic disorder of the lower motor neurons classified into four types based on clinical features, age of onset and the motor functions affected. ${ }^{1}$ All four types of SMA involve almost all of the skeletal muscles; only the muscles innervated by cranial nerves are unaffected, excluding those innervated by the hypoglossal nerve. ${ }^{1}$ Rarely, there is also localised involvement of the spinal cord. $^{2}$ Type I SMA may present from birth, within the first three months of life or after three months with patients having a limited ability to sit upright., ${ }^{2,3}$ In the majority of cases, the main cause of SMA is a homozygous deletion of the survival of motor neuron 1 (SMN1) gene. ${ }^{4}$

In Oman, autosomal recessive SMA is the most common genetic disease of the lower motor neurons. ${ }^{5}$ In addition, the country has one of the highest incidences of this disease worldwide, with approximately every one in 6,000 live births affected. ${ }^{5}$ According to unreported data, between 6-8 new cases of SMA are seen every year at the Sultan Qaboos University Hospital (SQUH), a tertiary hospital in Muscat, Oman. Furthermore, staff at SQUH have observed that these children often have an acute presentation with a significant progression of weakness within days of onset. The majority of children in Oman with type I SMA have a homozygous SMN1 gene deletion. ${ }^{5}$ This case report describes a young male patient with muscle weakness restricted to the lower limbs who was found to have SMA. To the best of the authors' knowledge, this is the first case reported from Oman of segmental SMA involving only the lower limbs.

\section{Case Report}

A 10-year-old boy from Salalah, Oman, presented to SQUH in 2015 with muscular weakness confined to the lower limbs. The patient had had a delayed onset of walking, with his parents noting the lower limb weakness only when he first began to walk. At 

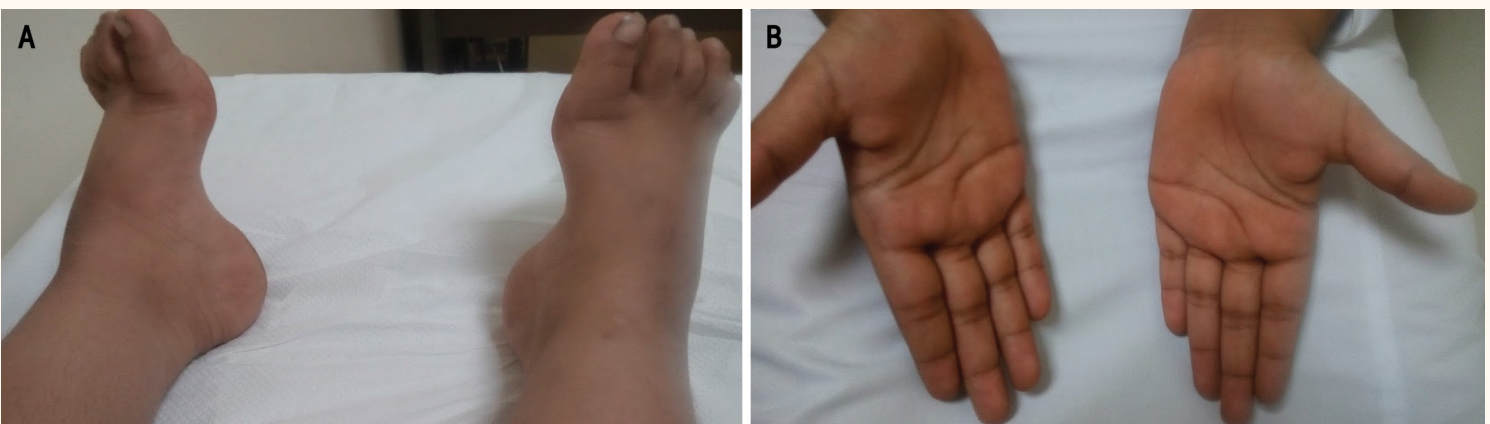

Figure 1: Photographs of a 10-year-old Omani boy with muscle weakness restricted to the lower limbs showing (A) bilateral pes cavus and (B) normal hands. The presence of a homozygous deletion within the survival of motor neuron 1 gene confirmed a diagnosis of spinal muscular atrophy.

presentation, he was able to sit up on his own, but had difficulty getting up and needed support from both hands. After standing, he was able to walk with a wide-based waddling gait and foot drop in both feet. When walking, he could only move slowly, frequently fell and had difficulty climbing stairs. There were no complaints regarding his upper limbs. Moreover, he had no problems swallowing and there were no respiratory symptoms. The patient seemed intelligent and had been ranked first in his class at school. His parents reported that the weakness in the lower limbs had remained the same over the past three years. His routine day-to-day activities were not affected, although he could not take part in various school activities or sports. In terms of family history, his parents mentioned that his maternal uncle aged 32 years old had had a similar presentation in early childhood. The patient had four siblings, none of whom displayed similar symptoms.

On examination, the patient's higher mental functions and cranial nerves were normal, with no tongue fasciculation. The power and tone of the upper limbs was normal. The hands had normal grip and power and the shoulder girdle muscles had normal power, with no winging of the scapula at rest or with resistance. The deep tendon reflexes were preserved in the upper limbs. The lower limbs looked bulky but were weak and the patient had difficulty lifting his legs up from the bed. There was no evidence of any wasting of the hip girdle or thigh muscles; however, there was wasting of the small muscles of both feet. The abduction and adduction power at the hips was $4 / 5$, flexion and extension at the knees was $3 / 5$ and dorsiflexion and planter flexion at the ankles was $3 / 5$. He had bilateral pes cavus and the long toe flexors and extensors were weak with a power of 2/5 [Figure 1]. He could walk on his heels but not on his toes and Gowers' sign was positive. Both knee and ankle reflexes were absent; however, sensation was normal all over the lower limbs.
The results of a routine blood work-up were normal, although the patient's serum creatine kinase level was slightly elevated at $600 \mathrm{IU} / \mathrm{L}$ (normal range: 50-350 IU/L). Motor and sensory nerve conduction studies in the upper limbs were normal. In the lower limbs, distal motor latency was mildly delayed in all nerves, although sensory nerve conduction was normal. The compound muscle action potential was reduced overall as compared to the upper limbs. Magnetic resonance imaging (MRI) scans of the brain, spine and pelvis were normal. Genetic testing revealed the homozygous absence of the SMN1 gene, confirming the diagnosis of SMA. Unfortunately, the family refused to consent to further genetic testing of any other family members. At the time of writing, the patient was undergoing physiotherapy at a local hospital in Oman.

\section{Discussion}

This case report describes an Omani boy with localised weakness of the lower limbs in whom a homozygous SMN1 gene deletion was identified via genetic testing. To the best of the authors' knowledge, this type of SMA has not previously been reported from this country; moreover, no cases with similar presentations of segmental SMA with homozygous SMN1 gene deletions are available in the current literature. Further genetic testing of the patient's family would have helped to determine the nature of inheritance of the condition as well as the carrier status; unfortunately, this could not be performed due to lack of consent. Patients with autosomal dominant distal SMA predominantly involving the upper limbs have been previously reported. ${ }^{6}$

Several variants of SMA not linked to the SMN1 gene exist, including scapuloperoneal SMA, SMA with pontocerebellar hypoplasia, X-linked infantile SMA with arthrogryposis, SMA with respiratory distress type 1, congenital distal SMA and distal SMA type V/ 
Charcot-Marie-Tooth disease type $2 \mathrm{~d} .{ }^{2}$ Of these, distal SMA with autosomal dominant inheritance involving the upper limbs is most common. ${ }^{2}$ SMA type III with SMN1 gene deletion may present in early childhood; affected children usually survive till adulthood and have a very slow progression of the disease. ${ }^{7,8}$ With regards to the present case, it is possible that the patient had a differing phenotype of SMA type III resulting in weakness of only the lower limbs. ${ }^{9}$ As such, there may be a progression of weakness over time, eventually spreading to the upper limbs.

There are reports of isolated upper limb or lower limb weakness related to anterior horn cell loss. ${ }^{8-10}$ Benign juvenile focal amyotrophy of the upper limbs, also known as benign focal amyotrophy disorders of the limbs or Hirayama disease, was initially reported in Japan. ${ }^{10}$ Schröder et al. reported a case of intrinsic motor neuron disease of the lower cervical spinal cord in which an MRI revealed localised spinal cord atrophy and flattening. ${ }^{11}$ In another case, Huang et al. reported that movement-induced myelopathy could also be an underlying mechanism of Hirayama disease; however, an autopsy revealed only loss of the anterior horn cells without any other changes. ${ }^{12}$ Hirayama disease is a sporadic disorder, although familial cases have been reported. ${ }^{6}$ Similar to cases of upper limb atrophy, researchers have also reported amyotrophy restricted to the lower limbs, particularly the calf muscles. ${ }^{13}$ However, this disease is usually seen in adults, does not progress and there is no evidence of sensory loss; moreover, there are no upper motor neuron features or SMN1 gene deletions in such patients and MRI scans of the spine are normal. ${ }^{13}$

Clinically, segmental SMA resulting in weakness of the lower limbs should be differentiated from hereditary motor sensory neuropathy, chronic immunemediated demyelinating neuropathy, distal myopathy, cauda equina syndrome and myeloradiculopathy. Examinations of the spine and any sensory abnormalities, nerve conduction and genetic tests and, if required, muscle/nerve biopsies can aid in confirming a diagnosis. To date, physiotherapy remains the main mode of treatment for SMA. However, the antisense oligonucleotide gene therapy drug nusinersen has recently been approved as treatment to prevent the progression of the disease. ${ }^{14}$

\section{Conclusion}

To the best of the authors' knowledge, this is the first case of segmental SMA with SMN1 gene deletion reported from Oman. This form of SMA, with involvement of only one part of the body, is a rare condition. Physiotherapy is currently the mainstay of treatment although recent advances in gene therapy could be beneficial.

\section{References}

1. Munsat TL, Davies KE. International SMA Consortium meeting: (26-28 June 1992, Bonn, Germany). Neuromuscul Disord 1992; 2:423-8. doi: 10.1016/S0960-8966(06)80015-5.

2. D’Amico A, Mercuri E, Tiziano FD, Bertini E. Spinal muscular atrophy. Orphanet J Rare Dis 2011; 6:71. doi: 10.1186/17501172-6-71.

3. Bertini E, Burghes A, Bushby K, Estournet-Mathiaud B, Finkel RS, Hughes RA, et al. 134th ENMC International Workshop: Outcome measures and treatment of spinal muscular atrophy, 11-13 February 2005, Naarden, the Nether-lands. Neuromuscul Disord 2005; 15:802-16. doi: 10.1016/j.nmd. 2005.07.005.

4. Lefebvre S, Bürglen L, Reboullet S, Clermont O, Burlet P, Viollet L, et al. Identification and characterization of a spinal muscular atrophy-determining gene. Cell 1995; 80:155-65. doi: 10.1016/0092-8674(95)90460-3.

5. Koul R, Al Futaisi A, Chacko A, Rao V, Simsek M, Muralitharan S, et al. Clinical and genetic study of spinal muscular atrophies in Oman. J Child Neurol 2007; 22:1227-30. doi: 10.1177/088 3073807306268

6. Andreadou E, Christodoulou K, Manta P, Karandreas N, Loukaidis P, Sfagos C, Vassilopoulos D. Familial asymmetric distal upper limb amyotrophy (Hirayama disease): Report of a Greek family. Neurologist 2009; 15:156-60. doi: 10.1097/ NRL.0b013e31818d6717.

7. Dastur RS, Gaitonde PS, Khadilkar SV, Udani VP, Nadkarni JJ. Correlation between deletion patterns of SMN and NAIP genes and the clinical features of spinal muscular atrophy in Indian patients. Neurol India 2006; 54:255-9. doi: 10.4103/00283886.27147 .

8. Al-Jumah M, Majumdar R, Al-Rajeh S, Awada A, ChavesCarbello E, Salih M, et al. Molecular analysis of the spinal muscular atrophy and neuronal apoptosis inhibitory protein genes in Saudi patients with spinal muscular atrophy. Saudi Med J 2003; 24:1052-4.

9. Deymeer F, Serdaroğlu P, Poda M, Gülșen-Parman Y, Ozçelik T, Ozdemir C. Segmental distribution of muscle weakness in SMA III: Implications for deterioration in muscle strength with time. Neuromuscul Disord 1997; 7:521-8. doi: 10.1016/S09608966(97)00113-2.

10. Hirayama K. [Juvenile muscular atrophy of the distal upper limb: Three decades of description and it's treatment]. Rinsho Shinkeigaku 1993; 33:1235-43.

11. Schröder R, Keller E, Flacke S, Schmidt S, Pohl C, Klockgether T, et al. MRI findings in Hirayama's disease: Flexion-induced cervical myelopathy or intrinsic motor neuron disease? J Neurol 1999; 246:1069-74. doi: 10.1007/s004150050514.

12. Huang YL, Chen CJ. Hirayama disease. Neuroimaging Clin $\mathrm{N}$ Am 2011; 21:939-50. doi: 10.1016/j.nic.2011.07.009.

13. Felice KJ, Whitaker $\mathrm{CH}$, Grunnet ML. Benign calf amyotrophy: Clinicopathologic study of 8 patients. Arch Neurol 2003; 60:1415-20. doi: 10.1001/archneur.60.10.1415.

14. Food and Drug Adminitsration, U.S. Department of Health and Human Services. FDA approves first drug for spinal muscular atrophy. From: www.fda.gov/newsevents/newsroom/ pressannouncements/ucm534611.htm Accessed: Apr 2017. 